\title{
Mandibular Metastasis of a Signet Ring Cell Carcinoma of the Breast in a Patient who Underwent Bilateral Mastectomy more than 25 Years Earlier
}

\author{
Francisco Santaolalla ${ }^{\mathrm{a}} \quad$ Cosme Ereño $^{\mathrm{b}} \quad$ Agustin Martínez $^{\mathrm{a}}$ Ana Sánchez del Rey ${ }^{\mathrm{a}} \quad$ Aitor Zabala $^{\mathrm{a}}$ \\ ${ }^{a}$ Department of Otolaryngology, \\ ${ }^{\mathrm{b}}$ Department of Pathology, Basurto Hospital, Bilbao, School of Medicine, University of the Basque Country, Spain
}

\section{Key Words}

Mandible $\cdot$ Metastasis · Breast cancer $\cdot$ Signet ring cells

\section{Summary}

Background: Metastatic tumors account for less than 1\% of all malignant tumors occurring in the oral cavity. Case Report: The clinical case of a 94-year-old patient with a mandibular tumor is reported here. The patient had undergone bilateral mastectomy more than 25 years before. An immunohistochemical study found hormone receptors in signet ring cells, suggesting a diagnosis of breast cancer metastasis. Conclusion: Immunohistochemical diagnosis and antineoplastic hormone therapy is the cornerstone in the management of this clinical case.

\section{Introduction}

Breast cancer is one of the most important tumors in the Western world because it is among the most common and causes both mortality and morbidity in affected women. In the United States, this tumor ranks second in incidence after lung cancer, and is the most fatal tumor in women, accounting for $15 \%$ of deaths from cancer [1]. Signet ring cell breast cancer was characterized in 1976 [2]. This type of tumor accounts for approximately $1 \%$ of all breast cancer [3]. It is characterized by a particularly high proportion of signet ring-shaped cells and is considered as a subtype of lobular carcinoma [4]. The presence of signet ring cells is associated with a more aggressive course and a greater trend to the development of gastrointestinal and gynecological metastases.

\author{
Schlüsselwörter \\ Unterkiefer · Metastasen · Brustkrebs · Siegelringzellen
}

\section{Zusammenfassung}

Hintergrund: Weniger als 1\% aller bösartigen Tumoren der Mundhöhle sind metastatische Tumoren. Fallbericht: Wir berichten über den Fall einer 94-jährigen Patientin mit einem Unterkiefertumor. Mehr als 25 Jahre zuvor war bei der Patientin eine bilaterale Mastektomie durchgeführt worden. Die immunhistochemische Untersuchung ergab Hormonrezeptoren in Siegelringzellen, was auf Brustkrebsmetastasen hindeutete. Schlussfolgerung: Die immunhistochemische Diagnosestellung sowie eine antineoplastische Hormontherapie bilden die Basis des Fallmanagements bei dieser Patientin.
Signet ring cells may occur in metastases only and not in the primary tumor, which may cause diagnostic uncertainty $[3,4]$.

On the other hand, metastatic tumors in the oral cavity are uncommon, accounting for approximately $1 \%$ of all malignant tumors occurring in the oral cavity. Within the oral cavity, metastatic tumors are most often located in jaw bones (85\%). The bone most commonly involved is the mandible (80-90\%), mainly at molar or retromolar sites [5]. Seventy percent of metastases in the oral cavity become evident after occurrence of the primary tumor, while $30 \%$ represent the first sign of extension of primary tumors of an unknown origin [6]. In most cases of metastases in the oral cavity, the primary tumor is located below the collarbone, and tumors most commonly metastasizing to the oral cavity are primary lung, breast, and

\section{KARGER}

Fax +497614520714

Information@Karger.de

www.karger.com (c) 2009 S. Karger GmbH, Freiburg

Accessible online at:

www.karger.com/brc 


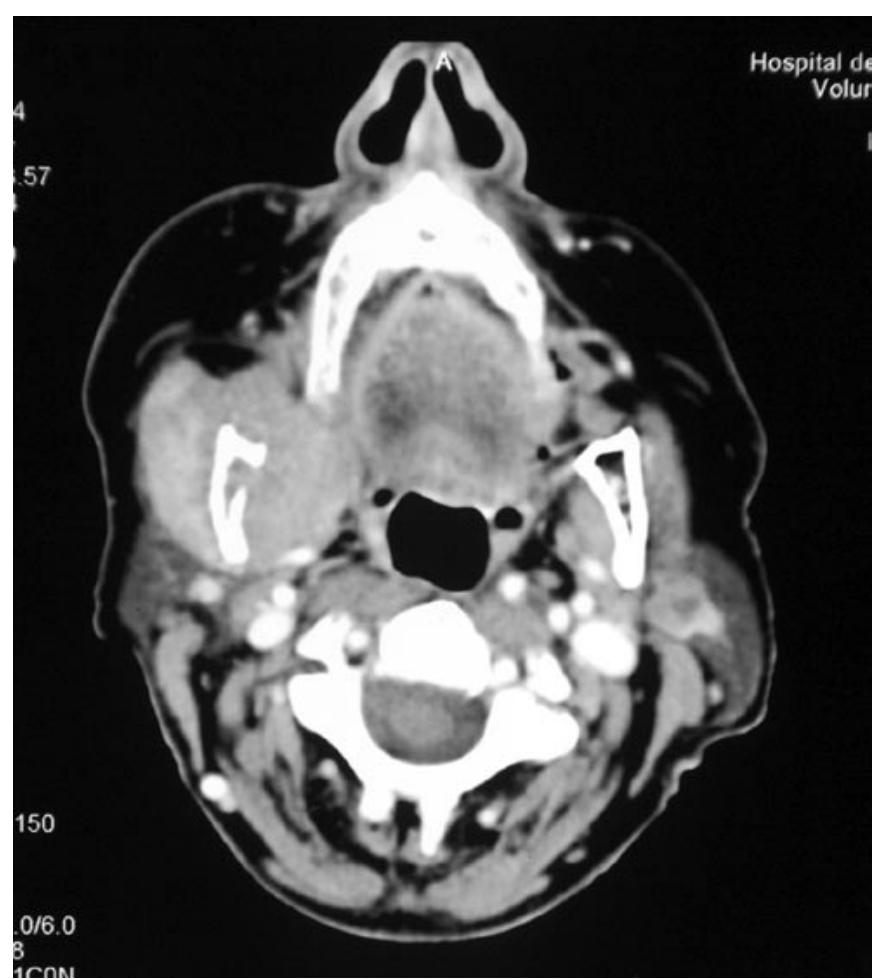

Fig. 1. Facial computed tomography scan showing a tumor destroying the bone walls of the right mandible.

kidney tumors which account together for approximately $50 \%$ of all oral metastases [5]. Oral metastases occur at a mean age of 50-60 years, but may appear at any age and with no significant sex differences [5]. As regards clinical signs and symptoms, oral metastases may be asymptomatic or may cause tumors, pain, ulcers, paresthesia, bleeding, periodontitis, trismus, or pathological fracture. Symptoms sometimes occur in a short period of time. An X-ray study most commonly shows a radiolucent osteolytic lesion with ill-defined margins. Osteoblastic images may be seen, and no evident radiographic changes will be found in $5 \%$ of cases [6].

In this article, we report the clinical case of a patient with a mandibular metastasis of a breast cancer she had experienced more than 25 years before. The metastasis was diagnosed based on the detection of hormone receptors using immunohistochemical techniques.

\section{Case Report}

A 94-year-old woman attended the office complaining of the presence of a right mandibular tumor for the past 3 months. On palpation, a hard non-tender submucosal tumor, adhered to the ramus of the mandible, was felt. Oral cavity examination did not reveal the existence of any ulcer or wound, and cervical examination to assess the status of lymph node chains was normal.

The patient reported a history of hypertrophic cardiomyopathy, urinary incontinence, and appendectomy, as well as surgery for anal fistula and inguinal hernia. She also reported to have suffered from breast car-

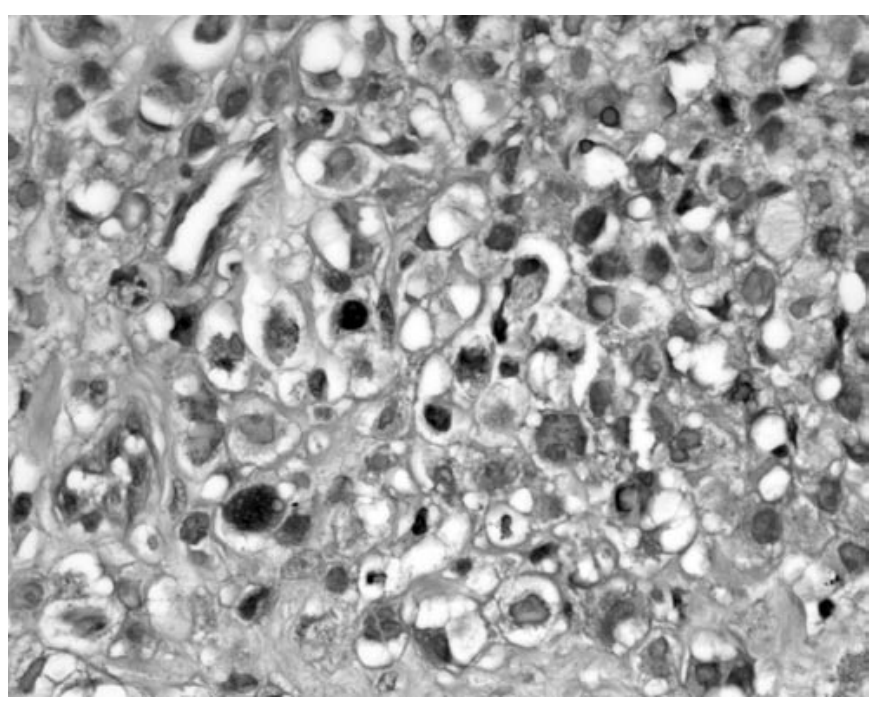

Fig. 2. $P A S$ and alcian blue stain; original magnification $\times 40$. Alcian blue-positive magenta bodies and signet ring eccentric nuclei are shown.

cinoma that was treated by excision of the right and left breasts 34 and 26 years ago, respectively. The patient also said that she had received postoperative supplemental treatment with radiotherapy, but because of the time elapsed and the fact that she had been seen at another center in another town, no more data could be obtained about these episodes.

A computed tomography (CT) scan with intravenous contrast from the skull base to the neck revealed a soft tissue mass in the right side of the neck that extended from the infratemporal fossa to the submaxillary gland. This mass caused destruction of the bone walls of the right mandible and infiltrated muscles and adjacent fatty planes (fig. 1). A fine needle aspiration revealed the presence of an infiltrating epithelial neoplasm that grew forming PAS- and alcian blue-positive cell cords and nests with irregular, hyperchromatic, and eccentric nuclei (signet ring) (fig. 2). Proliferating cells expressed strong and diffuse immunoreactivity to keratins AE1-AE3 and GCDFP-15 (gross cystic disease fluid protein), with a rate of estrogen and progesterone receptors $>90 \%$, consistent with a diagnosis of metastasis from a signet ring cell carcinoma of a breast origin. HER2 status of the metastasis was measured by immunohistochemistry, and the overexpression of the c-erB2 protein was scored as 3/3. The work-up study adopted for the identification of an unknown primary tumor was completed by performing thoracic and abdominal CT and positron emission tomography (PET) scans that were normal. Skeletal scintigraphy showed increased uptake of the radiotracer in the mandible of the right side suggesting metastatic bone involvement.

Based on the diagnosis of a mandibular metastasis of a breast carcinoma and because of the age of the patient, antineoplastic hormone therapy with letrozol $2.5 \mathrm{mg}$ /day was prescribed. Fifteen months after starting treatment, the patient has experienced a complete remission of the metastatic mandibular tumor and remains under regular medical checks.

\section{Discussion}

Patients with breast cancer remain exposed for many years to the risk of dissemination of the disease because metastases may appear after very long disease-free intervals of up to 20 years during which the disease remains completely silent. In this sense, guidelines for breast cancer follow-up and management have been recently updated [7]. 
In our case, the patient experienced a mandibular metastasis 26 and 34 years after undergoing mastectomy. Thus, in a patient diagnosed with a neoplastic disease, who has a lesion in the oral cavity, the presence of a metastatic lesion should be suspected. However, in $30 \%$ of the cases, oral metastases are the first sign of a primary malignant tumor of as yet unknown origin [5], and a high suspicion index is therefore required to establish a diagnosis, particularly in cases where metastases may have a similar histopathological appearance to other primary intraoral lesions, e.g. an oral epidermoid carcinoma or a lung epidermoid carcinoma [6]. So, a metastatic dissemination of a breast cancer also requires differential diagnosis with a second primary tumor. The risk of confusion increases when diagnosis and treatment are performed at different centers, as occurred in our case, so that not all prior information may be available. It should also be noted that signet ring differentiation may appear in metastases from a breast cancer regardless of whether or not the primary breast tumor had signet ring cells [8]. However, tests for cytokeratins, CK-7 and CK-20, and GCDFP-15, as well as hormone receptors, are proposed for differential diagnosis of the breast origin of carcinomas and their metastases [9]. Thus, in the reported case proliferating cells showed immunoreactivity to keratins AE1-AE3 and GCDFP-15, with a $>90 \%$ rate of estrogen and progesterone receptors. This is an odd phenomenon, because the dedifferentiation involved in the presence of signet ring cells in breast cancer metastases is not associated to a loss of expression of hormone receptors.

Occurrence of a metastatic lesion in the oral cavity is usually a poor prognostic sign indicating a disseminated neoplastic disease and suggesting a fatal outcome, and less than $10 \%$ of patients survive at 4 years of diagnosis [5]. Surgery is usually performed when the primary tumor is controlled and no additional metastases are found. In cases where the oral metastasis is the only one present, adequate surgical treatment may slightly improve the prognosis. When soft tissue metastases are very uncomfortable because of pain, bleeding, infection, or interference with chewing, palliative excision of the lesion should be performed. In our case report, the patient was treated with antineoplastic hormone therapy with letrozol, and she is showing no symptoms 1 year later.

In summary, a rare case of breast cancer metastasis in the oral cavity of a patient who was bilaterally mastectomized 25 years earlier is reported. Immunohistochemical diagnosis and antineoplastic hormone therapy are the cornerstones in the management of this clinical case.

\section{Conflict of Interest}

The authors have declared that no conflict of interest exists.

\section{References}

1 Greenlee R, Hill-Harmon M, Murray T, Thun M Cancer statistic 2001. CA Cancer J Clin 2001;51:1536.

2 Steinbrecher JS, Silverberg SG: Signet-ring cell carcinoma of the breast. The mucinous variant of infiltrating lobular carcinoma? Cancer 1976;37:828840.

3 Eltorky M, Hall JC, Osborne PT, el Zeky F: Signet-ring cell variant of invasive lobular carcinoma of the breast. A clinicopathologic study of 11 cases. Arch Pathol Lab Med 1994;118:245-248.

4 Liu SM, Chen DR: Signet-ring cell carcinoma of the breast. Pathol Int 2000;50:67-70.
5 Hirsberg A, Buchner A: Metastatic tumours to the oral region. An overview. Eur J Cancer B Oral Oncol 1995;6:355-360.

6 Hirsberg A, Leibovich P, Buchner A: Metastatic tumors to the jaws: analysis of 390 cases. J Oral Pathol Med 1994;23:337-341.

7 Khatcheressian JL, Wolff AC, Smith TJ, Grunfeld E, Muss HB, Vogel VG, Halberg F, Somerfield MR, Davidson NE; American Society of Clinical Oncology: American Society of Clinical Oncology 2006 update of the breast cancer follow-up and management guidelines in the adjuvant setting. J Clin Oncol 2006;24:5091-5097.
8 Raju U, Ma CK, Shaw A: Signet ring variant of lobular carcinoma of the breast: a clinicopathologic and immunohistochemical study. Mod Pathol 1993; 6:516-520.

9 Tot T: The role of cytokeratins 20 and 7 and estrogen receptor analysis in separation of metastatic lobular carcinoma of the breast and metastatic signet ring cell carcinoma of the gastrointestinal tract. APMIS 2000;108:467-472. 